\title{
La Disputa de Tortosa y las semillas judeoconversas del materialismo del siglo XVII
}

\author{
José SÁNCHEZ TORTOSA
}

\begin{abstract}
RESUMEN
La historia del judaísmo sefardí desde la Baja Edad Media hasta la Modernidad y sus diatribas contra el cristianismo, que pretende ser su resolución teológica y que, por tanto, lo considera momento abolido, indica la dirección de las corrientes de pensamiento, teológico, filosófico y aun político, que cristalizarán en el propio devenir del judaísmo moderno y en escuelas filosóficas que constituyen caldo de cultivo para un materialismo cuya culminación sistemática más acabada es la obra del judío sefardí de Ámsterdam Benedictus de Espinosa.
\end{abstract}

PALABRAS ClAVE: Disputa de Tortosa, Espinosa, conversos, judaísmo sefardí, mesianismo

\begin{abstract}
The history of Sephardic Judaism, from the late Middle Age to Modernity, and its diatribes against Christianity, which claims to be its theological resolution and, therefore, considers it abolished time, points out the direction of theological, philosophical and even political thought, which crystallize in the evolution of modern Judaism itself and in philosophical schools that are breeding grounds for a given materialism, the fullest systematic culmination of which is the work of Amsterdam-born, Sephardic Jew Benedictus de Espinosa.
\end{abstract}

KEYWORDS: Disputation of Tortosa, Espinosa, converts, sephardic judaism, mesianism

La historia del judaísmo occidental o sefardí, eminentemente español, desde la Baja Edad Media hasta la Modernidad, es campo de estudio indispensable para el historiador de las ideas. Sus avatares marcan las líneas maestras por las que discurren las corrientes de pensamiento, teológico, filosófico y aun político, que cristalizarán en el propio devenir del judaísmo y en escuelas filosóficas sin precedentes próximos. Por decirlo sin más, las controversias internas y externas en las que se ve inmerso el judaísmo hacen germinar mucho antes de la llegada del Renacimiento ${ }^{1}$ el caldo de cultivo de un proto-materialismo y de un proto-ateísmo que no verán su culminación sistemática más acabada hasta la composición de la obra del judío sefardí de Ámsterdam Benedictus de Espinosa y cuyas resonancias se pueden leer en los Pensées de Pascal, autor de un pensamiento teológico que explota en el corazón mismo de la crisis de la Iglesia Católica en el siglo XVII (Contrarreforma y Jansenismo). En esa configuración, tallada con la paciencia de la Historia, es central, a la escala de lo teológico, lo filosófico y, como veremos, lo político, la controversia de Tortosa (1413-1414), en la que un converso dominico y doctores del

\footnotetext{
${ }^{1}$ L. SUÁREZ, La expulsión de los judios, Barcelona, Ariel, 2012, 270.
} 
Talmud enfrentan posiciones y miden fuerzas en una disputa cuyas consecuencias marcan, en buena medida, el destino de los reinos cristianos y del judaísmo sefardí moderno, y más genéricamente, del pensamiento filosófico europeo. En esa batalla doctrinal se juega la esencia del vínculo teológico y ontológico entre Ley Vieja y Ley Nueva, su relevancia institucional y política y los canales por los cuales es definida la herejía. Pero es preciso remontarse un par de siglos para ir siguiendo los cauces por los cuales el fenómeno de referencia fue cuajando. Mencionaremos algunos de estos mojones sin los cuales apenas es comprensible:

\section{Constitutio pro iudaeis. Protección y tolerancia}

A finales del siglo XII, en la Europa occidental el estatuto jurídico de los judíos se basaba en su dependencia de los reyes y nobles, que les proporcionaban protección y de los cuales éstos obtenían beneficios económicos. En los reinos españoles, Alfonso VI, tras la reconquista de Toledo (1085), regula su condición legal poniéndolos bajo el amparo de la ley, pero no cómo súbditos, sino como huéspedes cuya seguridad y libertad son fruto de la generosidad más que derechos legalmente reconocidos ${ }^{2}$. En esta situación, la Constitutio pro indaeis (1199), firmada por el Papa Inocencio III, establecía el cuadro mínimo de derechos que debían ser otorgados por los reyes a los judíos ${ }^{3}$ : los judíos deben ser protegidos por las autoridades cristianas para su posterior conversión y no pueden ser obligados a bautizarse. La importancia institucional de esta medida estriba en un punto de máxima relevancia doctrinal: el judaísmo es considerado legítimamente la génesis del cristianismo, comparten parte del libro sagrado y por eso la Torá constituía para la Iglesia Católica la hebraica veritas, parte primigenia, pero incompleta, u obsoleta, de la verdad cristiana $^{4}$. Sin embargo, en este lazo, que permite entender la protección garantizada a los judíos por parte de las instituciones eclesiásticas oficiales y, debido acaso a motivos más materiales, por parte de los reyes, se encuentra ya en potencia la vuelta del revés que hace del cristianismo herejía del judaísmo, siendo éste su génesis, y, por motivos paralelos, convierte al judaísmo en una herejía recalcitrante del cristianismo, abolida ya por la llegada del Mesías e intolerable a la larga por su obstinación en el error. La protección,

\footnotetext{
${ }^{2}$ Ibidem, 14.

${ }^{3}$ Ibidem, 23.

${ }^{4}$ Ibidem, 13.
} 
conviene recordarlo contra el abuso del vocablo en el marco de lo políticamente correcto y de lo filosóficamente inane, es ofrecida desde la tolerancia, es decir, desde una posición de superioridad que permite (tolera) la desviación del otro. Estos aspectos estallarán en las disputas de París, Barcelona y Tortosa.

\section{Concilio de Letrán. Los límites jurídicos del judaísmo}

No es contradictorio, por tanto, que en esa corriente en la cual las relaciones del cristianismo regio y papal con el judaísmo se reconfiguran se tomen medidas para restringir y, así, definir los espacios legales que se dejan a la minoría. El mismo Inocencio III convocó el IV Concilio de Letrán (1215), del cual salieron varios decretos por los cuales se instaba a las autoridades a situar a los judíos en barrios separados (kahal) ${ }^{5}$ y se imponía la obligación a los judíos de llevar un distintivo en la ropa ${ }^{6}$. Significativamente, la primera medida ya se estaba llevando a efecto mucho antes, propiciada por los reyes porque facilitaba la protección de los judíos, y era aceptada por las propias aljamas. En cuanto a la segunda de ellas, los reyes españoles, Fernando III y Jaime I de Aragón, solicitaron al Papa la exención de tales medidas en sus dominios, donde los judíos estaban protegidos por una legislación que garantizaba su dependencia y seguridad.

\section{La sombra de Maimónides}

La Guía de Descarriados de Maimónides es publicada en lengua árabe en 1190, en Egipto. Su difusión genera sacudidas en el seno del judaísmo rabínico sefardí, una vez empezó a circular la traducción al hebreo de la obra por las aljamas españolas, debido a su "racionalismo"7 en la lectura de las Escrituras y en la interpretación de las leyes de la naturaleza desde la Revelación, siguiendo la línea aristotélica también abierta por Averroes en el contexto intelectual musulmán. Este racionalismo empieza a resultar peligroso para los doctores de la Ley más tradicionalistas. En 1232, Rabí Salomón ibn Abraham, de Montpellier, propone la prohibición de la lectura de las obras de

\footnotetext{
${ }^{5}$ Ibidem, 24.

${ }^{6}$ Ibidem, 29, 62 y ss; Y. BAER, Historia de los judíos en la España cristiana, Zaragoza, Riopedras, 1981 (1959), 107; Á. AlCALÁ, Los judeoconversos en la cultura y sociedad españolas, Madrid, Trotta, 2011, 30.

${ }^{7}$ La mayor parte de los historiadores emplean este término, motivo por el cual es mantenido en este trabajo, a pesar de que supone un sonoro anacronismo. Acaso sea más adecuado el de intelectualismo, como opuesto a fideísmo o voluntarismo, categorías más propias de los estudios sobre filosofía medieval.
} 
Maimónides, cuya influencia llevaba a ciertos intelectuales judíos, próximos a la Corte y, por tanto, miembros de una elite, a interpretar alegóricamente el Talmud. El asunto traspasa el círculo del judaísmo cuando Salomón ibn Abraham acude a los dominicos para advertirles de que el maimonismo es por su racionalismo tan peligroso para cristianos como para judíos ${ }^{8}$. El averroísmo, perseguido por las autoridades musulmanas, parecía respirar en la corriente generada por Maimónides dentro del judaísmo9 ${ }^{9}$ Sin embargo, en este caso, el delito fue contemplado como asunto propio por las eminencias cristianas, ${ }^{10}$ ya que la Ley judía (Antiguo Testamento) constituye, como ya hemos visto, parte seminal de la Fe cristiana. Por ello, la polémica tuvo como consecuencia la implicación de las autoridades cristianas (del Santo Oficio) en los asuntos internos de los judíos ${ }^{11}$.

\section{El converso Donín en París. Ley oral contra ley escrita}

Antes de la Disputa de Barcelona, un judío converso, Nicolás Donín ${ }^{12}$, anatemizado por la comunidad judía por negar la validez de la ley oral, denunció el Talmud ante Gregorio IX, que lo condenó el 3 de octubre de 1240 para Francia, Inglaterra y la Península Ibérica ${ }^{13}$. Las acusaciones contra el Talmud, a través de Donín, tenían como referencia a los caraítas (lectores o literalistas) ${ }^{14}$. Sostenían que los aggadot ${ }^{15}$ y los balajot ${ }^{16}$ del Talmud contienen blasfemias contra los cristianos y la moral, imputándoles un contenido teológico del que, como automatismos institucionales y consuetudinarios plagados de antropomorfismos, carecían ${ }^{17}$. Donín empleaba el propio Talmud, que conocía bien, en sus argumentos contra el judaísmo rabínico. En particular, focalizaba la cuestión en tres

\footnotetext{
8 Y. BAER, Historia de los judíos en la España cristiana, 107-108; L. SUÁREZ, La expulsión de los judíos, 67-68.

${ }^{9}$ L. SUÁREZ, La expulsión de los judios, 59.

${ }^{10}$ Ibidem, 68.

${ }^{11}$ Y. BAER, Historia de los judios en la España cristiana, 114.

${ }^{12}$ L. SUÁREZ, La expulsión de los judios, 71.

${ }^{13}$ Y. BAER, Historia de los judios en la España cristiana, 168.

${ }^{14}$ Ibidem. El caraísmo es una secta judía fundada en el s. VIII por Anán ben David que niega la autoridad de la ley oral y admite sólo la ley escrita o Biblia, frente a los rabbanitas, que aceptan la ley oral y siguen fieles al judaísmo tradicional.

${ }^{15} \mathrm{La}$ Aggadá es la parte de la literatura rabínica que no trata directamente de la interpretación normativa de la ley. Comprende elementos ideológicos, históricos, folclóricos, legendarios...

${ }^{16}$ La Halajá es la parte de la literatura rabínica que se ocupa de explicar los principios y normas legales y de conducta religiosa que deben regir la vida judía.

17 Véase antecedentes de esta polémica teológica en L. SUÁREZ, La expulsión de los judíos, 59-61.
} 
puntos $^{18}$ : incumplimiento de la Ley de Moisés por parte de los rabinos, que dicen haber recibido directamente de Dios una revelación oral, recogida en el Talmud; el judaísmo tradicional como herejía contra el Antiguo Testamento y contra el cristianismo; y los insultos contra la fe cristiana recogidos en el Talmud (contra la Virgen María y Jesús, especialmente). Aceptar estas conclusiones suponía invertir la concepción que del judaísmo, al que se toleraba y protegía, tenía hasta ese momento la Iglesia católica desde San Agustín ${ }^{19}$ e Inocencio III (Constitutio pro iudaeis, 1199). El Papa Gregorio IX, en carta enviada el 9 de junio de 1239 al arzobispo de París y a los reyes de Francia, Inglaterra, Castilla, Aragón y Portugal, ordena que el 3 de marzo de 1240 se requisen ejemplares del Talmud para ser examinados y enviados al fuego los que incurran en lo denunciado por Donín ${ }^{20}$. Luis IX, rey de Francia, obedeció la orden y organizó una disputa entre Donín y rabinos de París. En ella, Donín afirmaba que los judíos incumplían la Ley de Dios que les obligaba a reconocer al Mesías en Jesús y habían inventado una ley distinta a la escrita, no revelada por tanto, sino inventada por los hombres ${ }^{21}$. El Canciller del Estudio General (Universidad) de París decretó el Talmud como herético para cristianos y judíos, hecho de capital relevancia pues muestra hasta qué punto se impugnaba, desde coordenadas cristianas, la tradición oral talmúdica como perversión de la Torá, integrada en el corpus bíblico. En 1247, fueron atendidas las peticiones de los judíos y, por orden del Papa Inocencio IV, se les devolvieron los ejemplares del Talmud después de haber borrado las referencias a Jesús y los gentiles ${ }^{22}$. La consecuencia conceptual fue que se atribuía a los talmudistas la responsabilidad de la ceguera del pueblo de Israel, incapaz de ver la verdad de la venida del Mesías en la figura de Jesús por el alejamiento del Talmud con respecto a la ley escrita de la Biblia, considerada hasta ese momento hebraica veritas ${ }^{23}$. De hecho, el argumento de que la desviación se halla en la Tradición oral, no en la Ley escrita, fue el esgrimido por muchos de los conversos afines al maimonismo ${ }^{24}$. En 1242, Jaime I autorizó a los frailes de las órdenes mendicantes a predicar en las sinagogas, disposición que acabó convirtiéndose en norma establecida para toda la cristiandad. En

\footnotetext{
18 L. SUÁREZ, La expulsión de los judios, 72.

19 Y. BAER, Historia de los judios en la España cristiana, 15.

${ }^{20}$ L. SUÁREZ, La expulsión de los judios, 73.

21 Ibidem, 74.

${ }^{22}$ Y. BAER, Historia de los judios en la España cristiana, 168.

23 L. SUÁREZ, La expulsión de los judios, 77-78.

${ }^{24}$ L. SuÁREZ, La expulsión de los judios, 61.
} 
1263, incluyó en la prohibición del Talmud la última parte de la Mishnah Torah de Maimónides, es decir, el tratado Sophetim. De modo que la percepción del judaísmo empieza a mutar. De reserva espiritual y matriz del cristianismo pasa a ser error teológico cuyo empecinamiento político e institucional hay que corregir. $\mathrm{Y}$ en esta mutación el papel de los conversos, como Donín, fue clave. Por esa vía, el racionalismo de la obra de Maimónides, línea de continuidad con el averroísmo y, por extensión, con el aristotelismo pagano, desemboca en el universo intelectual cristiano a través de intelectuales judíos que lo toman como referencia crítica en relación con el judaísmo talmúdico tradicional (de la tradición oral). Por filiación bíblica, el judaísmo no es ajeno a la doctrina cristiana, como sí lo es el islam. Es una herejía acaso más dolorosa, más íntima, más dañina para la fe de Cristo.

\section{La Disputa de Barcelona. Sin pueblo no hay Rey}

En julio de 1263, se forzó a Nahmánides (Bonastrug de Porta) ${ }^{25}$ a mantener una disputa en Barcelona con el converso Pablo Cristiano, en presencia del rey Jaime I, el obispo de la ciudad, los dominicos Raimundo de Peñafort ${ }^{26}$, maestro general de la Orden de los Dominicos, quien al parecer pidió a su discípulo S. Tomás que escribiera la Suma contra gentes $^{27}$ y Raimundo Martín ${ }^{28}$, cuya obra, Pugio Fidei29 ${ }^{29}$ 1278, también fue encargo de Peñafort. Pablo Cristiano ${ }^{30}$ pretendía demostrar que el Mesías ya había llegado en la figura de Jesús; que era humano y divino; que murió para la expiación de los pecados; y, lo fundamental, que con su advenimiento los mandamientos del judaísmo habían sido

\footnotetext{
${ }^{25}$ El relato de M. NAHMÁNIDES está recogido en La Disputa de Barcelona, BN Publishing, 2007.

${ }^{26}$ L. SUÁREZ, La expulsión de los judios, 65 y ss.; 115-116.

27 «Deseando ardientemente [San Raimundo] la conversión de los infieles rogó al eximio doctor [rogavit eximium...] en Theologia Fr. Tomás de Aquino que escribiese algún libro contra los errores de los infieles... Cumplió aquel Maestro lo que requería el ruego humilde de tan gran padre [quod tanti patris bumilis deprecatio requirebat y escribió la obra que se intitula Summa contra gentiles, que no tiene igual en su género.» Citado por L. A. GETINO, La Summa contra Gentes y el Pugio Fidei, Vergara, 1905, 13; cf., 37.

${ }^{28} \mathrm{Su}$ presencia no es admitida por todos los historiadores si bien no parece dudoso que la impronta de la controversia influyó decisivamente en su obra. Véase C. DEL VALLE RODRÍGUEZ (ed.), La controversia judeocristiana en España (desde los orígenes hasta el siglo XIII), Madrid, Consejo Superior de Investigaciones Científicas, 1998, 304.

${ }^{29}$ R. MArtini, Pugio fidei adversus Mauros et Judaeos, Lipsiae, Haeredes Friderici Lanckii, 1687.

${ }^{30}$ Y. BAER, Historia de los judios en la España cristiana, 169; 172; 174, 646; J. PÉREZ, Historia de una tragedia. La expulsión de los judios de España, Madrid, Austral, 2009, 39; L. SUÁREZ, La expulsión de los judios, 106 y ss.; J. LOMBA, «Controversia racionalista en el pensamiento medieval judeoespañol» en U. MACÍAS y R. IZQUIERDO (eds.), El judaísmo, uno y diverso, Cuenca, Universidad Castilla-La Mancha, 2005, 138, 141, 143; A. KANIEVSKY, «Fuentes para el estudio de la apologética antijudía (siglo XIII-XVI)», DavarLogos 9.2 (2010), 191.
} 
abolidos $^{31}$. Por su parte, Nahmánides trató de probar que los pasajes aludidos no admitían interpretación cristológica; que Jesús no fue rey de los judíos ("si no hay pueblo, no hay rey"32); condición que se exige al Mesías además de ser descendiente de David (tribu de Judá); que se puede, contra lo que él mismo creía, ser judío sin aceptar las aggadot del Talmud; y, sobre todo, que la principal discrepancia entre judaísmo y cristianismo no reside en la creencia en el Mesías ${ }^{33}$. Además, combatió el dogma cristiano de la condición divina de Jesús. Al reconocer Nahmánides que no cabía creer literalmente algunas aggadot Pablo Cristiano presentó la posición de su oponente como contradictoria al reconocer implícitamente que el Talmud contiene falsedades ${ }^{34}$. Algunas autoridades del clero, franciscanos y nobles propusieron dar fin a la disputa ante el riesgo de altercados. El sábado posterior a la interrupción de la disputa, el rey asistió al sermón que Pablo Cristiano dio en la sinagoga anunciando la ocultación que los maestros judíos hacían a sus fieles y la venida del Mesías, y él mismo habló a los judíos, hecho inaudito en la Edad Media. Al día siguiente, Nahmánides se despidió del rey, del que recibió 300 sueldos y volvió a su casa ${ }^{35}$. Finalmente, marchó a Jerusalén. El rey firmó cuatro disposiciones en las que se establecía la autorización a los dominicos para predicar en las sinagogas, revisar los libros hebreos y desarrollar la acción evangelizadora, además de quemar el ejemplar que Nahmánides redactó sobre la disputa. Raimundo de Peñafort insistía en los argumentos de la misma, en especial, en que los talmudistas mantenían a los fieles judíos en su ceguera con respecto a Jesús como verdadero Mesías. Estos argumentos aparecen en la Suma contra gentiles de S. Tomás. Clemente IV, en su bula Damnabili perfidia Iudeorum reconoció el método de Pablo Cristiano en la disputa.

\section{E1 fracaso de la alternativa a la usura como base económica de los judíos}

En febrero de 1348, en la Corte de Alcalá de Henares, Alfonso XI manda redactar un Ordenamiento jurídico ${ }^{36}$ para eliminar la usura prohibiendo a judíos y musulmanes el

\footnotetext{
31 Y. BAER, Historia de los judios en la España cristiana, 169; L. SUÁREZ, La expulsión de los judíos, 111.

32 M. NAHMÁNIDES, La Disputa de Barcelona, \12; 49 (Salmos, 72, 8).

33 Ibidem, $\int 47$.

34 L. SUÁREZ, La expulsión de los judios, 112-113.

35 Y. BAER, Historia de los judios en la España cristiana, 174.

${ }^{36}$ L. Serrano, Los conversos D. Pablo de Santa María y D. Alfonso de Cartagena, Madrid, Escuela de estudios hebraicos, 1942, 9; J. AMADOR DE LOS Ríos, Historia social, política y religiosa de los judíos de España y Portugal,
} 
préstamo a interés y abrir a los judíos la posibilidad de poseer fincas en las tierras de realengo y dedicarse a la ganadería y la agricultura. Esta legislación presenta como motivo la pertenencia de los judíos al monarca y su interés en que así siga siendo, con el objetivo ulterior de que acaben integrados en la fe católica, tal como estamos viendo a lo largo de este recorrido:

[E]ra su voluntad [la del Rey] que los judíos se mantengan en nuestro sennorio, e asy lo manda la sancta yglesia, por que aun se an a tornar a nuestra fe e ser salvos, segunt se falla por las profecias. ${ }^{37}$

Nunca se llegó a aplicar. La oposición por parte de sectores de la sociedad que veían en la legislación un perjuicio para sus intereses, como los propietarios de tierras, los judíos cortesanos ricos o los tesoreros reales, frenó su puesta en marcha. Baer sostiene que a medio plazo esa legislación hubiera sido fatal para el judaísmo en su conjunto, pues habría descendido un puesto en el escalafón socioeconómico. Los motivos que el Rey pudo tener para semejante infructuosa propuesta legislativa no están claros. Sin embargo, hay dos puntos que en su estilo casi apologético Amador de los Ríos destaca y merecen ser tenidos en cuenta: combatir el odio al judío asociado a la imagen tópica del usurero y arraigar a los judíos a las tierras de sus reinos al hacerse propietarios y herederos. Estuvieran o no estas razones subjetivamente en la medida propuesta por Alfonso XI, ofrecen dos piedras de toque con las cuales desbrozar los pormenores de esa pinza causal que en el fenómeno aquí estudiado componen los factores ideológicos y los económicos, tan materialmente determinados los unos como los otros, según nuestro análisis.

\section{Las Matanzas de 1391}

Las matanzas de judíos, cuyo foco se produce en Sevilla pero que se propagan por buena parte de la Península, se dan en la confluencia de varios episodios críticos y marcan un cambio irreversible en la situación de los judíos hispanos ${ }^{38}$. Tras la muerte del obispo de

1874, Madrid, Aguilar, 1979, II, 46 y ss.; Y. BAER, Historia de los judios en la España cristiana, 402; L. SUÁREZ, La expulsión de los judíos, 199.

${ }^{37}$ J. AMADOR DE LOS RíOS, Historia social, política y religiosa..., II, 46; Y. BAER, Historia de los judíos en la España cristiana, 402; L. SUÁREZ, La expulsión de los judios, 200.

${ }^{38}$ Y. BAER, Historia de los judios en la España cristiana, 531 y ss. 
Sevilla, Pedro Gómez Barroso, en 1390, el arcediano Fernando Martínez se hace con el control de la diócesis. A ello se une la muerte de Juan I. Hereda el trono Enrique III, niño aún, por lo cual se instituye un consejo de Regencia, débil políticamente. El acceso al poder eclesiástico de un exaltado conjugado con la fragilidad de la monarquía propició el desencadenamiento de la persecución de judíos (expulsados ya de Inglaterra y Francia) por parte de las masas populares ${ }^{39}$, instigada, a espaldas del poder político y de la propia Iglesia, por los mensajes de un miembro del clero. El descontento social contra las clases privilegiadas en momentos de debilidad de los mandos políticos ${ }^{40} \mathrm{y}$ crisis económica fue encauzado hacia los judíos ${ }^{41}$, por mucho que apareciera encubierto o legitimado teológicamente:

Las gentes de los pueblos, lo uno por tales predicaciones, lo ál por voluntad de robar; otrosí no habiendo miedo del rey, por la edad pequeña que había y por la discordia que era entre los señores del reino por la cuestión del testamento [de Don Juan] y del Consejo, ca non preciaban cartas del rey ni mandamientos suyos ciudades ni villas ni caballeros; por ende aconteció este mal. Todo fue codicia de robar, según pareció, más que devoción. ${ }^{42}$

El impacto económico que estos episodios tenían en perjuicio de los reyes y de los nobles se amortiguó por el elevado número de conversos, que vinieron, en muchos casos, a desempeñar las funciones financieras mayoritariamente en manos de judíos hasta ese momento. Éstos, menos necesarios que antes, quedaron también más desprotegidos.

\section{El converso de hoy contra el converso de mañana ${ }^{43}$}

Selomó Haleví, nacido en $1350^{44}$ y bautizado con el nombre de Pablo de Santa María el 21 de julio de 1390, poco antes de las matanzas antijudías ${ }^{45}$, valido de Enrique III ${ }^{46}$, pasó

\footnotetext{
39 «Generalmente los reyes, los de Sefarad y Francia, los nobles, los sabios y todos los principales del país amaban a los judíos; sólo eran odiados por el populacho que los envidiaba.» (S. IBN VERGA, La vara de Yehudah, Barcelona, Riopiedras, 1991 (1550), \24).

${ }^{40}$ L. SUÁREZ, La expulsión de los judios, 241 y ss.

${ }^{41}$ «El odio social hacia el rico se convierte en odio religioso hacia el no católico.» (J. PÉREZ, Historia de una tragedia, 56; véase también 55 y ss.); Cf. L. SUÁREZ, La expulsión de los judíos, 258-259.

${ }^{42}$ Canciller LÓPEZ DE AYALA, citado por J. PÉREZ, Historia de una tragedia, 56.

${ }^{43}$ Y. BAER, Historia de los judios en la España cristiana, 570 y ss.; L. SUÁREZ, La expulsión de los judios, 269.

${ }^{44}$ L. SERRANO, Los conversos..., 10.
} 
de ser rabino mayor de la judería de Burgos (vinculado a círculos fariseos) a ser obispo en esa misma ciudad en 1416, nombrado por Benedicto XIII (Pedro de Luna), Papa de Aviñón desde 1394. Su relación fue muy cercana hasta la destitución de Luna como Papa por el Concilio de Constanza (1417). Benedicto XIII es autor de una bula contra los judíos (1415), cuya ejecución encargó al hijo de Pablo, Gonzalo de Santa María, arcediano de Briviesca ${ }^{47}$. También tuvo vínculos con Vicente Ferrer, aunque no pudo influir en su conversión, que es anterior a su encuentro personal, pues el orate llega a Castilla en 141148. Sus referencias centrales son S. Tomás, el Pugio Fidei de Raimundo Martín y las obras de los también conversos Pedro Alfonso de Huesca (Diálogo contra los judíos) y Alfonso de Valladolid, de nombre Abner de Burgos antes de su bautismo en 1321 (Mostrador de Justicia) ${ }^{49}$. Sus obras principales son las Adiciones a las anotaciones de Nicolás de Lira sobre la Biblia (1429) y el Scrutinium Scripturarum (1432), escrito en forma de diálogo entre Saulo y Pablo, en cuya figura se plasma el nexo dialéctico entre judaísmo y cristianismo, aludido al comienzo. Quiso disputar con Hasday Crescas ${ }^{50}$, antiguo correligionario, pero la influencia de éste en la corte era aún sólida y no se plegó a los deseos del converso. Pablo estaba convencido del error de la doctrina que él mismo había enseñado y que el Mesías había venido ya. El error no está en la Torá sino, precisamente, en los que no la siguen fielmente. Sin perjuicio de que factores materiales, como la posibilidad de promocionar social y políticamente ${ }^{51}$ o la mera seguridad personal e, incluso, la supervivencia ante los desastres de la comunidad judía, jugaran papel relevante, desde el punto de vista doctrinal y filosófico, la clave parece radicar en el descubrimiento de la verdad del cristianismo en la Torá misma. El judaísmo volvía a sangrar por la herida doctrinal abierta por Donín. En su correspondencia con Yehosua

${ }^{45}$ L. Serrano, Los conversos..., 20, 27; A. CASTRO, España en su historia: cristiano, moros y judíos, Madrid, Crítica, 2001 (1948), 146; L. SUÁREZ (La expulsión de los judíos, 268), J. PÉREZ (Historia de una tragedia, 59) y Á. AlCALÁ (Los judeoconversos en la cultura y sociedad españolas, 75) también dan el año 1390, pero Y. BAER (Historia de los judios en la España cristiana) da 1391, indicando explícitamente que se produjo tras las matanzas de ese año.

${ }^{46}$ L. SerRanO, Los conversos..., 51. Fue Canciller Mayor del Rey y preceptor del futuro rey, su hijo, Juan II hasta sus 14 años.

${ }^{47}$ J. AMADOR DE LOS Ríos, Historia social, politica y religiosa..., III, doc. XX; L. SERRANO, Los conversos..., 62.

${ }^{48}$ L. SERRANO, Los conversos..., 57.

${ }^{49}$ A. DE VALLAdolid, Mostrador de Justicia, Opladen, Westdeutscher Verlag, 1994.

${ }^{50}$ L. SUÁREZ, La expulsión de los judíos, 269.

${ }^{51}$ Pablo dijo a Yehosua Halorquí la última vez que se vieron: «Lamento haber conseguido estos aparentes éxitos que no son más que vanidad y cosas sin sentido.» (Y. BAER, Historia de los judíos en la España cristiana, 575.) 
Halorquí ${ }^{52}$, antes de que éste se convierta también, afirma que el cristianismo no niega al judaísmo. La diferencia está en el reconocimiento de la venida del Mesías. Paradójicamente, algunos de los argumentos que Yehosua Halorquí opone a Pablo, como que el Mesías ha de ser de la estirpe de David y rey en sentido literal ${ }^{53}$, son los que luego recibirá en contra en la Disputa de Tortosa, hasta el punto de que se ha puesto en duda que sean administrativamente la misma persona ${ }^{54}$, ese imposible ontológico. De hecho, las dudas que empiezan a carcomer la fe de Halorquí parecen avivarse en su discusión con Pablo. ${ }^{55}$ Sería ésta una buena muestra del sintomático debilitamiento de los vínculos con la tradición de los judíos más cultos, proclives al intelectualismo o racionalismo ${ }^{56} \mathrm{de}$ los averroístas y Maimónides. Ese debilitamiento rompió en algunos personajes importantes, como los que estamos estudiando, en conversión al cristianismo ${ }^{57}$. Desde el punto de vista práctico, proselitista, la cuestión se jugaba en conseguir que los judíos se convencieran de que la conversión al cristianismo es el acto cabal del judaísmo verdadero, su corolario, que el cristianismo es el verdadero judaísmo, el judaísmo cumplido. La predicación de Vicente Ferrer y la política eclesiástica del Papa Benedicto XIII confluyen en esta dirección. El problema judío se resolvería sin violencia, "por la fuerza de la palabra y no de la espada" ${ }^{58}$. El principal obstáculo no eran las masas populares, verdadero destinatario de los esfuerzos proselitistas contenidos en las predicaciones y en las políticas eclesiásticas, sino los sabios talmúdicos y los rabinos conservadores.

\footnotetext{
${ }^{52}$ Yehosua Halorquí, bautizado Jerónimo de Santa Fe probablemente por Vicente Ferrer en 1412, médico del Papa Benedicto XIII y portavoz papal en la disputa de Tortosa (M. OrfaLí, El tratado "De Iudaicis erroribus ex Talmut" de Jerónimo de Santa Fe, Madrid, CSIC, 1987, 3 y 8 ss).

${ }^{53}$ Y. BAER, Historia de los judíos en la España cristiana, 576; M. ORFALÍ, El tratado "De Iudaicis erroribus ex Talmut" de Jerónimo de Santa Fe, 9. Hemos visto que estos aspectos se abordaron ya en la Disputa de Barcelona.

${ }^{54}$ Como Graetz y Zinberg. Véase M. Orfalí, El tratado "De Iudaicis erroribus ex Talmut" de Jerónimo de Santa Fe, 2.

55 Ibidem, 578.

56 Véase nota 7.

${ }^{57}$ La necesidad de investigar en la Biblia y en la tradición oral si Jesús es el Mesías esperado por el judaísmo lleva a Pablo de Santa María al cristianismo: «Y esta investigación es la puerta de la esperanza por la que he penetrado en la tradición de la Alianza — yo y los míos-, y ésta es la puerta del Señor por la que entrarán los justos (Salmos, 118, 20).» (Y. BAER, Historia de los judios en la España cristiana, 579).

${ }^{58}$ L. A. GeTiNO, La Summa contra gentes y el Pugio Fidei, 87.
} 


\section{Ordenamiento de Valladolid. La singularidad jurídica}

La tensión doctrinal, social y demográfica descrita desemboca en una legislación más restrictiva que las precedentes. La reina Catalina, por minoría de edad de Juan II, y sometida a la influencia de Vicente Ferrer y del converso Pablo de Santa María, extremo que no puede probarse según Serrano59, aprueba en 1412 un ordenamiento jurídico respecto a los judíos (las Leyes de Ayllón para Castilla) que establecía, como puntos de mayor impacto, los siguientes ${ }^{60}$ : retirada de la autonomía judicial de la aljama; prohibición de ciertos oficios: médicos, arrendatarios, boticarios, carniceros, zapateros...; obligación de llevar barba y pelo largo y marca distintiva en la ropa (rodela roja); obligación de vivir en barrios cerrados.

Se trataba de presionar jurídicamente para que la salida de la conversión fuera la más aceptable para los judíos. Sumado a las matanzas, el peso de las limitaciones legales iba dejando cada vez menor margen a la autonomía y pervivencia de las comunidades judías, que quedaban excluidas como grupo separado del resto de los súbditos. La existencia de un Estado dentro del Estado, de un sector de la población con estatuto jurídico diferenciado a efectos penales, tributarios, religiosos ${ }^{61}$, que implicaba perjuicios más que privilegios, pero que no dejaba de establecer planos legalmente distintos entre los súbditos, empieza a convertirse en un problema político para los Reinos cristianos de la Península Ibérica a medida que estos se van consolidando dentro del proceso que los llevará a convertirse en un Estado moderno centralizado, estructura política que exige una legislación más homogénea. De forma esquemática, se pueden ir reconstruyendo en virtud de este enfoque las líneas causales que culminan en la expulsión de 1492.

\section{La Disputa de Tortosa}

Iniciada el 7 de febrero de 1413, por el Papa Benedicto XIII ${ }^{62}$, se prolonga hasta el 19 abril de $1414{ }^{63}$. Jerónimo de Santa Fe pretendía demostrar que los argumentos a favor

\footnotetext{
59 L. SERRANO, Los conversos..., 57.

60 J. PÉREZ, Historia de una tragedia, 60; Y. BAER, Historia de los judios en la España cristiana, 594 y ss.; L. SUÁREZ, La expulsión de los judios, 273 y ss., J. AMADOR DE LOS RÍOS, Historia social, política y religiosa..., II, 127.

${ }^{61} \mathrm{~J}$. PÉREZ, Historia de una tragedia, 84-87.

${ }^{62}$ En el Concilio de Constanza se estaba decidiendo la legitimidad papal, en disputa por el Cisma de Occidente (L. SuÁREZ, La expulsión de los judios, 283).
} 
del mesianismo de Jesús estaban contenidos en la Biblia hebrea y en el Talmud ${ }^{64}$. El principal portavoz judío fue Astruc Haleví, además de Vidal de la Caballería, hijo de Benveniste, Ferrer Saladín (R. Zerahya Halevî) y José Albo ${ }^{65}$, estos dos últimos los únicos en no convertirse tras la disputa, según Amador de los Ríos ${ }^{66}$, extremo que los documentos no muestran. El equívoco puede derivarse de la renuncia de Astruc Haleví a defender el Talmud del 10 de noviembre de 1414, firmada por todos los rabinos presentes menos los dos anteriores ${ }^{67}$. También intervino Profeit Durán ${ }^{68}$. Los rabinos presentes eran principalmente discípulos de Hasday Crescas, fallecido en $1411^{69}$. Como factor que contribuyó al ambiente propicio para la disputa es preciso citar las predicaciones de Vicente Ferrer, exitosas entre el vulgo pero sin efecto entre los talmudistas ${ }^{70}$, lo cual apunta a una cuestión capital de matriz socioeconómica y con efectos de carácter práctico-político, tal como era presentada por los apologistas cristianos: los judíos estaban plegados a los caprichos y privilegios de sus élites, los rabinos y talmudistas. Por eso, el argumento de combate doctrinal, tomado del Pugio Fidei, se presentaba como el interés por liberar a las masas de esa tutela para que alcanzaran la verdadera $\mathrm{fe}^{71}$. Baer habla del encuentro entre Vicente Ferrer y Halorquí en Alcañiz, poco después de ser elegido rey de Aragón Fernando de Antequera, tras el cual se produce la conversión de Halorquí ${ }^{72}$. Aunque los dominicos llevaban desde los años

${ }^{63}$ Y. BAER, Historia de los judios en la España cristiana, 611 y ss.; J. PÉREZ, Historia de una tragedia, 60 y ss.; L. SUÁREZ, La expulsión de los judios, 282; J. AMADOR DE LOS RíOS, Historia social, política y religiosa..., II, 129 y ss.; A. PACIOS, La disputa de Tortosa, Madrid, Instituto Arias Montano, 1957; Á. AlCALÁ, Los judeoconversos en la cultura y sociedad españolas, 39 y ss.

${ }^{64}$ L. SUÁREZ, La expulsión de los judios, 281.

${ }^{65}$ El Scrutinium Scriptorum de PABLO DE S. MARÍA responde a una obra de este rabino (L. SERRANO, Los conversos..., 112).

${ }^{66} \mathrm{~J}$. AMADOR DE los Ríos, Historia social, política y religiosa..., II, 132; J. CARO BAROJA, Los judios en la España Moderna y Contemporánea, Madrid, Istmo, 2000 (1968), II, 417.

${ }^{67}$ M. ORFALÍ, El tratado "De Indaicis erroribus ex Talmut" de Jerónimo de Santa Fe, 6.

${ }^{68}$ S. IBN VergA, La vara de Yebudah, 169 y ss.; Y. BAER, Historia de los judios en la España cristiana, 613; Á. ALCALÁ, Los judeoconversos en la cultura y sociedad españolas, 40-41.

${ }^{69}$ Y. BAER, Historia de los judios en la España cristiana, 613.

${ }^{70} \mathrm{~J}$. AMADOR DE LOS RÍOS, Historia social, politica y religiosa..., II, 129.

${ }^{71}$ L. SUÁREZ ilustra esta cuestión refiriendo la declaración de un grupo de judíos, ya iniciada la disputa en febrero de 1413, que admitían la posibilidad de que el Mesías hubiera venido ya (La expulsión de los judíos, 282-283). BAER (Historia de los judíos en la España cristiana, 619) habla de que fueron obligados a hacer ese juramento: «La intención del papa no era abrir los ojos de los rabinos disputantes, que obstinada y pérfidamente persistían en mantener sus opiniones a toda costa; en verdad él se dirigía a las masas sencillas y sinceras para redimirlas del dominio de los rabinos y del yugo de la Torá.» (622).

72 «En ambos casos, el racionalismo aristotélico no les llevó a la increencia sino a la conversión.» (J. JiMÉNEZ LOZANO, Sobre judios, moriscos y conversos. Convivencia y ruptura de las tres castas, Valladolid, Ámbito Ediciones, 2002, 68.) 
60 y 70 del siglo XIII empeñados en la labor de conversión de los judíos, contexto en el que se encuadran los encargos ya mencionados de Raimundo de Peñafort a S. Tomás y a Raimundo Martín, además de la promoción de los estudios de árabe y hebreo para el análisis de los textos, es con Fernando I de Aragón cuando más proclive podría ser la corona a una política de esta naturaleza, tras las matanzas de 1391 y gracias a la influencia sobre el rey de Vicente Ferrer ${ }^{73}$.

Benedicto XIII abrió el acto con las siguientes palabras:

Vosotros, sabios judíos, sabed que no he venido ni os he hecho venir para demostrar cuál de las dos religiones es la verdadera pues sé que mi religión y mi creencia son las verdaderas, y que vuestra Torah lo fue, pero ha sido abolida. Sólo habéis venido porque Jerónimo dijo que él probaría por el Talmud de vuestros maestros, que conocéis la mayoría de vosotros, que el mesías ya ha venido. Por lo tanto, hablad en mi presencia únicamente de esa cuestión. ${ }^{74}$

En estas palabras aparece la referencia explícita a la necesaria abolición del judaísmo con la venida de Cristo $^{75}$. El cristianismo es el verdadero judaísmo ${ }^{76}$, el judaísmo puro, que una suerte de puritanismo judío, esto es, cristiano, reclama, el que regresa a sus fundamentos, por lo cual podríamos hablar incluso de un cierto fundamentalismo judaico cuya desembocadura inexorable es el cristianismo. Por decirlo de un modo gráfico, que depurará Pascal, en la Ley Antigua está ya prefigurada la ley Nueva. El judaísmo es semilla del cristianismo. E, incluso, Pascal distingue al judío carnal del espiritual, ${ }^{77}$ que no

73 Y. BAER, Historia de los judios en la España cristiana, 613.

${ }^{74}$ S. IBN VERGA, La vara de Yehudah, 171. También cita el pasaje J. AMADOR DE LOS Ríos, Historia social, política y religiosa..., II, 131, pero la única fuente es la obra de IBN VERGA. En las Actas no aparece.

75 J. PÉREZ (Historia de una tragedia, 86) cita un pasaje de la Crónica de los Reyes Católicos de FERNANDO DEL PULGAR, sobre la toma de posesión de fray Alonso de Burgos, obispo de Palencia en 1486 en la cual se escenifica institucional y ceremonialmente el carácter obsoleto del judaísmo con respecto al cristianismo, idea central en las pesquisas que estamos ofreciendo aquí: «Hubo grandes fiestas y especialmente lo regocijaron los moros y los judíos que moraban en la ciudad, que eran sus vasallos, los moros con diversas danzas e invenciones, y los judíos iban en procesión cantando cosas de su ley, y detrás venía un rabí que traía un rollo de pergamino en las manos, cubierto con un paño de brocado y éste decían que era la Torá, y llegado el obispo él hizo acatamiento como la ley de Dios, porque diz que era la Santa Escritura del Testamento Viejo, y con autoridad la tomó en las manos y luego la echó atrás, por encima de sus espaldas, a dar a entender que ya era pasada, y así por detrás la tornó a tomar aquel rabí; la cual fue ceremonia digna de ponerse en esta memoria, porque fue la última vez que se hizo, a causa que, después, de ahí a pocos años se tornaron cristianos.»

76 B. PASCAL, Pensées, Paris, du Seuil, 1978, L256, L267, L269, L276, L286.

77 Ibidem, L256, L286. 
es otro que el judío verdadero, el cristiano. O, por emplear la terminología matemática de Pascal, el Antiguo Testamento es figura, cifra o clave que el Nuevo Testamento, como profecía cumplida, descodifica ${ }^{78}$. Pascal, de hecho, cita el Pugio Fidei en este punto. ${ }^{79}$

La primera alocución de Jerónimo de Santa Fe en la apertura de la disputa se sustenta en una cita de Isaías ${ }^{80}$ :

Venid y hagamos cuentas... pero si rehusáis y os rebeláis, por la espada seréis devorados.

En una suerte de vuelta de tuerca, el proyecto de conversión voluntaria por persuasión («por la fuerza de la palabra y no de la espada») gira sobre el poder que la posición de fuerza permite en esos momentos, si bien el sentido no literal, sino espiritual de esas palabras según Jerónimo, era el de la llamada del Papa a los judíos para atraerlos a su seno pacíficamente y con libertad.

El propósito doctrinal y dialéctico del converso era probar que el verdadero Mesías ya llegó y que es Jesús de Nazaret, y hacerlo tomando como base argumentativa los propios textos hebreos, donde se encuentra ya la verdad del cristianismo en estado latente, como profecía o figura, según se desprende asimismo de las palabras ya citadas de Benedicto XIII en la apertura de la Disputa.

Jerónimo recurrió al siguiente silogismo, tal como lo recoge Baer ${ }^{81}$, para confirmar que la venida del Mesías se ha producido:

El hombre en quien se cumplieran las profecías mesiánicas es el Mesías. Es así que en Jesús se cumplieron todas las profecías mesiánicas; luego Jesús es el Mesías. ${ }^{82}$

Si se demostraba la verdad de la premisa menor no quedaría margen de maniobra para los judíos. Tendrían que admitir la verdad del cristianismo como judaísmo cumplido, como verdadero judaísmo. Jerónimo citaba pasajes del Talmud y del Midrás para su

78 Ibidem L257, L282.

${ }^{79}$ «Après sa mort [J. C.] saint Paul est venu apprendre aux hommes que toutes ces choses étaient arrivées en figures. » (Ibidem, L270); « Le vieux testament est un chiffre.» (Ibidem, L276).

80 Isaias, I, 18-21, según lo recoge BAER (Historia de los judios en la España cristiana, 615). Véase cita completa en A. PACIOS, La disputa de Tortosa, II, acta de la primera sesión.

${ }^{81}$ Y. BAER, Historia de los judíos en la España cristiana, 615.

82 «Ille in quo complentur omnia prophetice dicta de Messia, est Messia./In Christo complentur omnia prophetice dicta de Messia./Ergo Christus est Messia.» (Actas, Sesión primera, Conclusio, en A. PACIOS, La disputa de Tortosa, 12) 
propósito. La tesis de Baer es que ese material estaba sacado del Pugio Fidei, que, según este historiador, es una falsificación parcial de los textos judíos ${ }^{83}$. En buena medida, el peso de la apologética del converso estaba soportada por una versión distorsionada de los textos a los que afirmaba recurrir y que debía de conocer de primera mano. Pero lo que el tradicionalista judío vería como falsificación el nuevo judío, el converso, presentaba como el verdadero significado de los textos, rescatado de la tradición escrita y contaminado o pervertido por la tradición oral, talmúdica. En esa confrontación, el juego de pruebas y contrapruebas basculaba de la interpretación literal a la alegórica, con lo cual la posibilidad de una concordancia o acuerdo estaba neutralizada de antemano por las posiciones de partida. Por eso cabe preguntar por el verdadero propósito político, más allá del teológico y doctrinal, de la Disputa. Acaso deba ser entendido como la escenificación institucional de la decadencia del judaísmo aragonés y, por extensión, español, con consecuencias sociológicas, demográficas y económicas de gran impacto asociadas, sobre todo, a la ola de conversiones durante y después de la Disputa:

De un día para otro unos judíos que hasta entonces habían sido quienes mejor sostenían los bienes materiales y espirituales de su pueblo se convirtieron en cristianos, en ciudadanos respetados en su ciudad y en todo el reino, en juristas, oficiales del municipio y del Estado, con los mismos derechos y la misma concepción de la vida que los cristianos. ${ }^{84}$

Un aspecto esencial de la controversia era la condición del Mesías, qué requisitos teológicos e históricos prueban dicho estatuto. $\mathrm{Y}$ es aquí donde aparece un elemento clave para la historia del judaísmo en la diáspora: el carácter político de su mesianismo ${ }^{85}$, que se da entrelazado con principios teológicos. Astruc Haleví, en su intervención del 10 de febrero, afirmó la independencia de la salvación del alma de los judíos con respecto a la venida del Mesías: «sus almas serían salvas incluso aunque el Mesías no llegara

\footnotetext{
${ }^{83}$ Y. BAER, Historia de los judios en la España cristiana, 617; 619-621; 625, 626; L. SUÁREZ, La expulsión de los judios, 283. Véase M. ORFALÍ, El tratado "De Iudaicis erroribus ex Talmut", 190 y ss.

${ }^{84}$ Y. BAER, Historia de los judios en la España cristiana, 660; véase también 646 ss. y 709; L. POLIAKOV, Historia del antisemitismo, II. De Mahoma a los marranos, Barcelona, Muchnik, 1980 (1961), 188 y ss.; J. PÉREZ, Historia de una tragedia, 62; L. SUÁREZ, La expulsión de los judíos, 286; Á. ALCALÁ, Los judeoconversos en la cultura y sociedad españolas, 24.

${ }^{85}$ L. SUÁREZ, La expulsión de los judios, 282 y ss.
} 
nunca.» ${ }^{86} \mathrm{O}$, según hubo de matizar tras la acusación de blasfemia por parte del Papa, aunque no llegara hasta cerca del fin de los tiempos: «eciam quod non veniret usque prope finem mundi» ${ }^{87}$. Pero si la redención no depende de la llegada del Mesías, si un judío puede salvarse sin el advenimiento, ¿qué añade la llegada del Mesías al tiempo mundano de los hombres? La respuesta es, como hemos anticipado, política. El Mesías es la garantía de la restauración política (corporal, terrenal) de la nación judía. Es la Civitas Terrae de los judíos, la Jerusalén inferior, paso necesario para la Jerusalén superior (Civitas Dei). Es la institución terrena, unida a la reconstrucción del Templo ${ }^{88}$, que dota de sentido al mesianismo político, la instauración de nuevo del Estado de Israel: «ad bona temporalia et ad prosperitatem corporum consequendam expectaban Messiam». Me permito apuntar en esta idea, que late en una disputa del alcance teológico, filosófico e histórico que estamos viendo, la posible prefiguración o el caldo de cultivo del sionismo del XIX, como movimiento de secularización política del mesianismo salvífico. El vínculo de la promesa política con el culto mosaico se hacía depender, según los rabinos disputantes, de la Torá y los profetas, por lo cual todo pasaje del Talmud (las aggadot) que supusiera contradicción con esos principios debía ser interpretado figurative, según su estatuto de figura, alegóricamente ${ }^{89}$. Y ante la afirmación de Jerónimo de que la fe en el Mesías es uno de los trece principios del judaísmo, los rabinos opusieron que, si bien eso es cierto como dogma genérico, aunque Albo y Astruc Haleví llegaron a negarlo, lo cual no fue recogido en las actas según Baer, el momento de la venida no es uno de ellos. A partir de ese punto, mayo de 1413, la controversia gira en torno a los requisitos del Mesías, a su conditio sine qua non teológica, histórica, política ${ }^{90}$. Según los talmudistas, el Mesías congregaría al pueblo judío en su tierra y reconstruiría el Templo en Jerusalén. La respuesta del converso, recurriendo al ardid ya mencionado, fue afirmar el carácter interpretativo de esos textos, que debían ser leídos spiritualiter. El ardid, paradójicamente,

\footnotetext{
86 Y. BAER, Historia de los judíos en la España cristiana, 618; «quod iudei non ad finem eorum salvandi animas, sed dumtaxat ad bona temporalia et ad prosperitatem corporum consequendam expectaban Messiam, dicere habuit; nam anime eorum, eciam si nunquam veniret Messias, salve fierent.» (Actas, Sesión cuarta en A. PACIOS, La disputa de Tortosa, 40).

87 Ibidem.

88 Y. BAER, Historia de los judios en la España cristiana, 680, nota 8; 627.

89 Ibidem, 623, 626.

90 Ibidem, 638. El 17 de mayo de 1413, Jerónimo de Santa Fe resume las seis condiciones contempladas por el judaísmo (Actas, Sesión quincuagesimacuarta en A. PACIOS, La disputa de Tortosa, 459). La tercera, que citamos por su alcance, ya mencionado, es: «templum et Ierusalem materialiter erant edificanda.»
} 
tiene trazas averroístas. E, incluso, para ello, Jerónimo citó la Misné Torá de Maimónides ${ }^{91}$. A todo ello, hay que agregar que los doctores judíos alegaron que el Mesías no podía venir para cambiar la Ley, sino para hacerla cumplir y para liberar a los judíos de su cautiverio corporal. De nuevo, el cumplimiento de la Ley no puede concebirse desvinculado de la plataforma política, territorial, patrimonial ${ }^{92}$. Y esta apuesta está en la Escritura literalmente, no es parábola o metáfora de otra cosa ${ }^{93}$.

El peso de la Ley, en lo relativo a la salvación individual, fue tan enfatizado por los portavoces judaicos que a la pregunta de Jerónimo acerca de qué recompensa le esperaba a los que morían siendo cristianos, contestaron que merecer el jardín del Edén no depende de la esperanza en el Mesías, sino de las buenas obras y del cumplimiento de los preceptos de la Torá ${ }^{4}$. Sin embargo, con respecto a la redención del pueblo de Israel, los doctores judíos insistieron en que la llegada del Mesías no afectaba a la redención del alma sino a la liberación terrenal del Pueblo de Israel y el alumbramiento de una Era (Mesiánica) en la que no habría ya servidumbre en el mundo, ni para los judíos, aliviados de su cautiverio histórico, ni para los demás pueblos, integrados en la Ley Mosaica ${ }^{95}$. El quiliasmo mesiánico esgrimido por los rabinos en su defensa se dispara hacia una utopía armonista que prefigura los modelos de mesianismo político de varios siglos después.

Este sesgo mundano de la promesa mesiánica, según era presentada por los portavoces del Talmud, fue aprovechado por Jerónimo para reprocharles que se trataba de una promesa de bienes terrenales. Y los rabinos presentes admitieron que no hay explícitamente en La Torá referencia a otra cosa que a una prosperidad terrena, pero que ese Estado de Bienestar (mundano) hace posible por sí mismo los bienes espirituales. ${ }^{96}$

\footnotetext{
${ }^{91}$ Ibidem, 624, Actas, en A. PACIOS, La disputa de Tortosa, 157.

${ }^{92}$ L. SUÁREZ, La expulsión de los judíos, 283; Y. BAER, Historia de los judíos en la España cristiana, 625.

${ }^{93}$ Y. BAER, Historia de los judios en la España cristiana, 627.

${ }^{94}$ Ibidem, 628.

${ }^{95}$ Ibidem, 630.

96 «El judaísmo recogía así la tradición jurídica y sapiencial, sacerdotal y mesiánica de las fuentes bíblicas. La tradición ligada al poder estatal, quebrada por la pérdida del Estado y sus instituciones, quedaba recogida en la utopía mesiánica. El estudio de la Ley y la observancia de los preceptos debían contribuir a acelerar la venida del Mesías. A partir de la catástrofe del año 70 d. C., destruido el Templo y desvanecidas muchas de las esperanzas mesiánicas, el judaísmo se desarrolló en una línea metahistórica, con el acento puesto en lo eterno e inmutable de la vida, reglamentada ésta por la Torá y por la interpretación rabínica de la misma.» (J. TREBOLLE, La experiencia de Israel: profetismo y utopía, Madrid, Akal, 1996, 44)
} 
En general, en sus argumentaciones, los rabinos se acogieron más al método místico de Nahmánides, según lo califica Baer, que al "racionalista" de Maimónides. ${ }^{97}$ Latiendo en esta controversia se pueden detectar dos puntos de indudable relevancia y de un recorrido filosófico e histórico que no siempre se han calibrado en su justa medida. Uno es la inmortalidad individual del alma. ${ }^{98} \mathrm{El}$ otro es la diferencia entre la tradición escrita y la oral (aquí comparece el caso Donín), entre la Torá y el Talmud ${ }^{99}$.

Tal vez resulte pertinente recuperar, en este momento de la exposición, la figura de otro notable converso: Alfonso de Valladolid. ${ }^{100}$ Antes de su conversión se movía en círculos en los que se consideraba a Maimónides el más apropiado intérprete de la tradición judía. Ishac Policar (Pulgar) fue colega suyo, así como el filósofo Mosé Narboni, el cual reprocha a Abner un determinismo cerrado:

\begin{abstract}
Miré y he aquí que allí había un sabio de los más singulares de su tiempo al que yo había alcanzado a ver al final de sus días, el cual había compuesto un tratado sobre el Determinismo donde decía que "lo posible" no existe, sino que todo es inevitable, todo está predeterminado... Y este hombre, que se llamaba Abner, era muy sabio, por lo que no creo que dijera tales errores sino con intención. ${ }^{101}$
\end{abstract}

Ese determinismo, que, de modo rudimentario, apunta a la noción de causalidad necesaria de Espinosa y a la encrucijada ontológica que en Pascal supone la incapacidad del hombre para elegir su fe, late en una de las razones que contempla para explicar por qué los judíos no se acogen al arrepentimiento cristiano: «porque Dios no quiere que se produzca el arrepentimiento del pecador.» ${ }^{102}$ En esta obra, sostiene que en el judaísmo están soterrados dogmas cristianos, como la Encarnación o la Trinidad (El, Elohim,

\footnotetext{
${ }^{97}$ Y. BAER, Historia de los judios en la España cristiana, 646. Véase nota 7.

98 «Se acordaba de que ellos eran carne, un soplo que se va y ya no vuelve.» (Salmos, 78, 33); «la suerte de los hijos del hombre y la suerte de las bestias es la misma; la muerte del uno es como la muerte del otro; ambos tienen un mismo hálito y la superioridad del hombre sobre al bestia es nula, porque todo es vanidad. Ambos van al mismo lugar; ambos vienen del polvo y ambos vuelven al polvo.» (Eclesiastés, 3, 19-22). Sobre las diferencias entre saduceos y fariseos en este punto, véase F. JOSEFO, Las guerras de los judios, Madrid, Gredos, 1997, II, 162-167; R. LULIO, Libro del gentily los tres sabios, Madrid, UNED-BAC, 2007, 191; Y. BAER, Historia de los judíos en la España cristiana, 8 y ss.; J. CARO BAROJA, Los judíos..., 510 y ss.; J. PÉrez, Historia de una tragedia, 68; J. Mosterín, Los judios, Madrid, Alianza, 2006, 93.

${ }^{99}$ Y. BAER, Historia de los judios en la España cristiana, 631; 642.

100 Ibídem, 383 y ss; J. PÉREZ, Historia de una tragedia, 39; L. SUÁREZ, La expulsión de los judios, 189-191.

${ }^{101}$ Citado por BAER, 371.

102 Mostrador de Justicia, Ms. de París, fols. 29-30v, en Y. BAER, Historia de los judíos en la España cristiana, 373.
} 
Adonay) ${ }^{103}$. En un mundo pagano politeísta, haber presentado abiertamente la Estructura Trinitaria de Dios o la Encarnación de la Divinidad en el ser humano individual, y no sólo en el Intelecto Agente, podría haber llevado a las gentes a la idolatría mientras el monoteísmo no se hubiera afianzado suficientemente:

Por eso la Torá de Moisés no mencionó la recompensa en el mundo venidero y también por eso ocultó la Torá las trazas de la Trinidad, que únicamente mencionó en alusiones veladas. ${ }^{104}$

Como vemos, el argumento confluye paradójicamente con el problema de la lectura literal o de la figurativa de las escrituras, presente en Averroes y en Maimónides, según el cual los ritos y principios teológicos del judaísmo tienen un carácter pedagógico, ya periclitado en la visión del converso ${ }^{105}$. Así, en el carácter alegórico de la lectura de los textos sagrados, la inmortalidad individual del alma, puesta ya en cuestión por Averroes en función del Intelecto agente único y, con matices, por Maimónides, es expresión figurativa de una realidad distinta a escala de lo filosófico: el doble plano de lectura de los textos sagrados que ambos filósofos admiten, el propio del vulgo y las mentalidades infantiles, que se expresa en metáforas que el indocto ha de leer ad literam, y el interpretativo, reservados a los sabios, capaces de interpretar filosóficamente las alegorías figurativas de las Escrituras:

Para hablar de todas estas cosas se han utilizado las palabras homónimas, para que el vulgo las tomase en cierto sentido, a la medida de su inteligencia y según la debilidad de su concepción, mientras que el hombre perfecto, que ha recibido instrucción, pudiese tomarlas en otro sentido. ${ }^{106}$

\footnotetext{
103 C. DEL VAlLE, «La Tercera Carta Apologética de Abner de Burgos», Miscelánea de estudios árabes y hebraicos, Universidad de Granada, 37-38 (1991), 357-359.

104 Mostrador de Justicia, Ms. de Parma, fols. 21-27, en Y. BAER, Historia de los judios en la España cristiana, 383.

105 También J. DE SANTA FE hace alusión a esta cuestión citando a MAIMÓNIDES (A. PACIOS, La Disputa de Tortosa, I, 352). Según el filósofo judío, los rituales tenían la función de antídoto contra la idolatría, no verdadero valor teológico. Es inevitable relacionar esta idea con el automatismo pascaliano, el embrutecimiento (abêtissement) concebido como la anestesia ritual, repetitiva, sin la cual la creencia, por exceso de lucidez, no sería posible (Pensées, L418, L821).

106 M. MAIMÓNIDES, Guía de Descarriados, Madrid, Compañía Ibérico-americana de Publicaciones, 2010, I, intr., 24
} 
Los gérmenes conceptuales y programáticos del materialismo ${ }^{107}$ de los siglos XVII y XVIII, en los que cierto escepticismo, cierto epicureísmo, la negación de la inmortalidad del alma (saduceísmo) ${ }^{108}$ y su intelectualismo deísta son clave de bóveda, están ya sembrados aun antes de la aparición del Renacimiento, en estos vericuetos por los que el judaísmo sefardí va buscando salida material a las aporías que la Historia genera.

107 J. PÉREZ, Historia de una tragedia, 94-95; L. SUÁREZ, La expulsión de los judíos, 270. SUÁREZ habla de la influencia de un personaje tan notable dentro del judaísmo sefardí como HASDAY CRESCAS en Giordano BRUNO y PICO DELLA MiRANDOLA.

108 Aquí cabe citar el caso de la conocida como "secta atea de Medina del Campo", de 1460, cuyo lema era: «En este mundo no me veas mal pasar, que en el otro no me verás penar.» (L. POLIAKOV, Historia del antisemitismo, II, 189; J. JIMÉNEZ LOZANO, Sobre judíos, moriscos y conversos, 29; J. CARO BAROJA, Los judios..., 512; J. PÉREZ, Historia de una tragedia, 68; M. EsPOSITO, "Una manifestazione d'incredulità religiosa nel medioevo. Il detto dei "Tre impostori" e la sua trasmissione da Federico II a Pomponazzi» (1931), en Archivio storico italiano, Ser. 7, vol. 16 / (89) (1931) 3-48; y «Une secte d'hérétiques à Médina del Campo en 1459» (1936), en Revue d'bistoire ecclésiastique, vol. 32 (1936) 350-359). 